\title{
Chapter 5 \\ Urbanisation, Migration and the Anti-Poverty Programme in China
}

\author{
Houkai Wei and Hongjian Su
}

\begin{abstract}
From 1979 to 2018, China underwent rapid urbanisation and large-scale population migration. As a result, the permanent urban population increased by about 659 million, and the numbers of rural poor decreased by 754 million. However, as migration from rural to urban areas has increased, rural poverty has reduced while urban poverty is gradually increasing. The co-existence of both rural and urban poverty poses new challenges to development. In this chapter, we analyse the characteristics of China's internal migration and urbanisation process. We draw on relevant data to describe in detail the changes that have occurred since China's Reform and Opening-up, as well as China's programme in reducing rural poverty and current trends in urban poverty. As the rate of urbanisation in China enters a new phase, there is a growing imperative to improve and promote an integrated approach to both urban and rural development. We also discuss the new raft of anti-poverty and poverty-management measures.
\end{abstract}

Keywords Urbanisation $\cdot$ Migration $\cdot$ Anti-poverty programme $\cdot$ China

\subsection{Introduction}

Since China's 'reform and opening-up', urbanisation has increased rapidly. At present, the rate of urbanisation (the proportion of people living in urban areas) in China has reached 59.6\% (State Statistical Bureau 2019), and this is well above the world's overall level. Although the speed of this process is slowing down, it is still happening at a comparatively high rate. With urbanisation and large-scale population movement has come urban poverty. As a result, there has been a growing

H. Wei $(\bowtie) \cdot H . S u$

Rural Development Institute, Chinese Academy of Social Sciences, Beijing 100732, P.R. China

e-mail: wei_houkai@263.net

$\mathrm{H} . \mathrm{Su}$

e-mail: suhj@ cass.org.cn 
imperative to monitor and improve the quality of urbanisation. Chinese urbanisation in China has recently entered a new stage steered by moves towards significant quality improvement (Wei 2014, 2015).

In this chapter, we chart the various stages of China's internal migration and urbanisation process over the past four decades and the implications for urban poverty. The chapter consists of four parts. Section 5.2 describes the slowdown of urbanisation in China and the new stage of development oriented towards improving the quality or urban life. In Sect. 5.3, we investigate achievements in poverty reduction in rural China since the 'reform and opening-up'. In Sect. 5.4, we discuss urban poverty in the process of Chinese urbanisation, calculate the size of the population of urban poor using various methods, and analyse the multi-dimensional aspects of poverty within this population. Section 5.5 concludes with a brief overview and discussion.

\subsection{China's Urbanisation and New Stage of Development}

China's urbanisation rate has reached two major points of development in recent years (see Fig. 5.1). While internal migration from rural to urban areas has slowed, the rate of growth continues. The Chinese urbanisation rate increased from $17.92 \%$ in 1978 to $58.52 \%$ in 2017 , with an average annual increase of 1.04 percentage points. In the same period, the world's overall urbanisation rate increased from 38.48-54.82\%, with an average annual increase of 0.42 percentage points. From 2010 to 2011, China's urbanisation rate rose beyond $50 \%$, so that the country became a predominantly urban society (Wei 2013). The following year, China's urbanisation rate reached $52.6 \%$ to

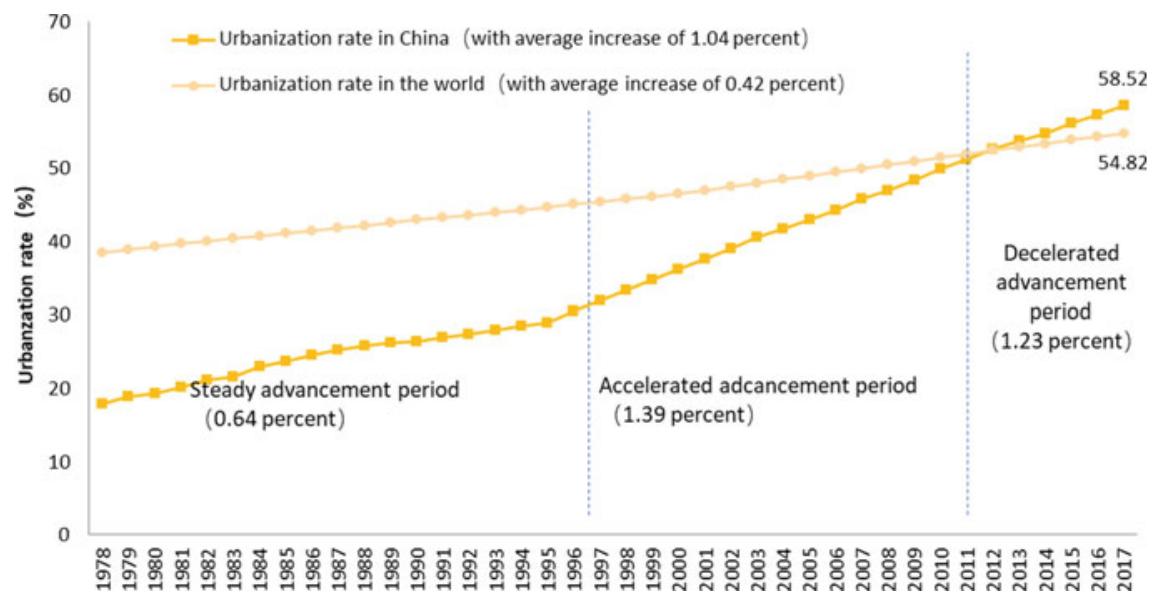

Fig. 5.1 Urbanisation rate in China and the world (1978-2017). Data sources Data on urbanisation rate in China is derived from China Statistical Yearbook (2018); data on the global rate of urbanisation is derived from data published by the World Bank: https://data.worldbank.org/indicator/sp. urb.totl.in.zs 
exceed the global urbanisation rate of $52.5 \%$ and continued to advance faster than the world average.

According to Northam (1979), China's urbanisation rate was less than $30 \%$ at the initial stage of development, growing from 30-70\% during the middle period of rapid development. The acceleration stage occurred from 30 to $50 \%$, with deceleration occurring between 50-70\%. Anything beyond 70\% occurs at the later stage of stable development (Wei 2014). China's urbanisation rate reached a turning point of $30 \%$ and 50\% in 1996 (30.48\%) and 2010 (49.95\%), respectively. From 1978 to 1996, it progressed steadily at a speed of 0.64 percentage points. From 1997 to 2010, it accelerated at a speed of 1.39 percentage points. The average speed slowed down during 2011 and 2017, with an average annual increase of 1.23 percentage points. If we project the $\mathrm{S}$-shaped curve alongside other forms of predictive research (Wei 2014), the Chinese urbanisation rate will reach $70 \%$ by around 2030 . The rate of urbanisation is expected to advance rapidly until reaching that point.

The rate of slowdown conforms to Northam's (1979) S-shaped curve of urbanisation. An eventual deceleration derives from a slowdown in migration and a reduced willingness among migrant workers to enter and settle in cities. Under the new steady-state of China's economy, the rate of increase in urban employment has also declined. The migration rate from rural areas has decreased with the downturn in economic growth and the substitution of capital to labour caused by the rapid rise in wages. According to annual monitoring and survey reports on migrant workers released by the National Bureau of Statistics since 2009, the rate of migration from rural areas has declined sharply since 2012 (see Fig. 5.2). In 2015 and 2016, the increase was only 630,000 and 500,000, respectively. It should be noted that in 2017 , the number of rural migrant workers increased by 2.51 million. However, these new

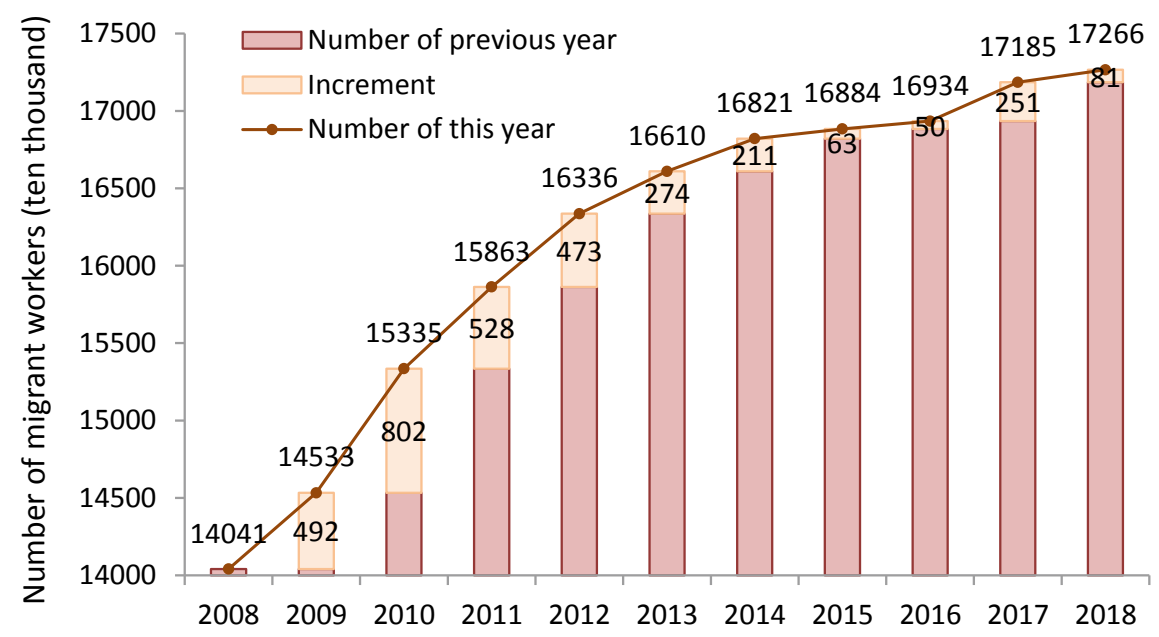

Fig. 5.2 Growth of migrant workers from rural areas of China in recent years. Data sources National Bureau of Statistics, annual monitoring and survey reports on migrant workers 
migrant workers mainly flowed from their villages to urban areas within their home provinces, which accounted for $96.4 \%$ of the increase of migrant workers from rural areas.

The annual increase revived during 2018 , rising to 810,000 . Due to a combination of government intervention and market forces, urban capital, technology, and talent have increasingly flowed into the countryside in recent years. This process is especially pronounced in the developed coastal areas such as the Delta of the Pearl and Yangtse Rivers where rural residents enjoy many benefits like homestead and collective dividends. Some urban residents are now trying to find ways to obtain rural hukou-household registration status that confers rights of access to local public services and welfare support (see Chaps. 1, 4 and 12) - through various channels. In the longer term, the trend will be towards a two-way free migration of urban and rural populations.

\subsubsection{Settlement Rates of Rural Migrants}

At the same time, the willingness of migrant workers to settle in cities varies across different regions. Factors that affect the willingness of rural migrants to settle in cities include a narrowing income gap between urban and rural residents, a continual increase in levels of urban-rural integration, and increasingly preferential rural policies. At present, in some megacities, where stricter hukou systems and settlement standards are implemented, rural migrant workers show a strong willingness to settle permanently. Other small and medium-sized cities have liberalised their hukou system and actively encourage rural workers to settle. Nevertheless, the overall willingness of rural workers to settle down has declined.

According to statistical surveys (see Table 5.1) conducted in 2014, the proportion of agricultural migrants prepared to settle longer-term in cities was relatively low, between 30 and 50\% except in Changzhou and Zhengzhou. The proportion of migrant workers willing to settle in cities and towns was only $41.5 \%$ in Zhongshan, $40.8 \%$ in Harbin, $41.1 \%$ in Yantai, 34.5\% in Fuling, 51.6\% in Ordos, $45.6 \%$ in Guang' an, and $46.2 \%$ in Shaanxi (see Table 5.1). The Survey on Dynamic Monitoring of Migrant Population in 2016 reveals that the willingness to settle as residents in the cities of immigration among the rural registered floating population was $58 \%$, while the willingness to settle down (including hukou registration in the cities of immigration) was only $30 \%$. These figures were much lower in small and medium cities (National Health Commission of the People's Republic of China 2018). This decline in rural workers' willingness to enter and settle in cities will slow the urbanisation rate and impact the urbanisation pattern (Wei 2019). 
Table 5.1 Results of survey on migrant workers' willingness to settle in cities (2014)

\begin{tabular}{|c|c|c|c|}
\hline Survey subject & City & Sample number & $\begin{array}{l}\text { Willingness to settle in } \\
\text { cities }(\%)\end{array}$ \\
\hline $\begin{array}{l}\text { Zhongshan Survey } \\
\text { Team of the National } \\
\text { Bureau of Statistics }\end{array}$ & Zhongshan & 82 & 41.5 \\
\hline $\begin{array}{l}\text { Changzhou Survey } \\
\text { Team of the National } \\
\text { Bureau of Statistics }\end{array}$ & Changzhou & 152 & 82.9 \\
\hline $\begin{array}{l}\text { Harbin Survey Team of } \\
\text { the National Bureau of } \\
\text { Statistics }\end{array}$ & Harbin & 341 & 40.8 \\
\hline $\begin{array}{l}\text { Yantai Survey Team of } \\
\text { the National Bureau of } \\
\text { Statistics }\end{array}$ & Yantai & 90 & 41.1 \\
\hline $\begin{array}{l}\text { Zhengzhou Survey } \\
\text { Team of the National } \\
\text { Bureau of Statistics }\end{array}$ & Zhengzhou & 120 & 75.0 \\
\hline $\begin{array}{l}\text { Fuling Survey Team of } \\
\text { the National Bureau of } \\
\text { Statistics }\end{array}$ & Fuling & 84 & 34.5 \\
\hline $\begin{array}{l}\text { Ordos Survey Team of } \\
\text { the National Bureau of } \\
\text { Statistics }\end{array}$ & Ordos & 186 & 51.6 \\
\hline $\begin{array}{l}\text { Shaanxi Statistics } \\
\text { Bureau }\end{array}$ & $\begin{array}{l}\text { Various districts and } \\
\text { counties }\end{array}$ & 1100 & 46.2 \\
\hline $\begin{array}{l}\text { Urban-rural Survey } \\
\text { team of Guang'an } \\
\text { Bureau of Statistics }\end{array}$ & Guang'an & 500 & 45.6 \\
\hline
\end{tabular}

Data sources Collated according to relevant data released by the statistical departments

\subsubsection{New Type of Urbanisation: A Period Marked by Quality Improvement}

With the slowdown in the urbanisation process, strategic planning has begun to emphasise quality improvement issues. At the end of 2013, the Central Work Conference on Urbanisation clearly pointed out the necessity to 'advance people-centred urbanisation.' Further clarity was provided by the Chinese State Council and the Central Committee of the Communist Party of China in 2014. A plan for the period 2014-2020 made an explicit commitment to quality improvement and a more 'people-centred' approach taking complete account of Chinese characteristics. The aim was to implement a more holistic approach by improving the spatial layout and addressing ecological and cultural heritage in any new developments. 
The State Council also issued the Comprehensive Pilot Programme for National New-type Urbanisation at the end of 2014, further emphasising the need for a peoplecentred approach. Pilot work considered various aspects, including the citizenisation of agricultural migrants, investment and financing mechanisms, reform of the rural homestead system, innovations and reforms in administrative management and institutional mechanisms, so as to identify models that can be up-scaled or replicated. The practical issues of development and the change at a strategic level show that China has entered a period of comprehensive improvement in the quality of urbanisation. It is imperative to advocate a shift from rapid urbanisation to a more quality-oriented process. Recent measures to improve the quality of the urbanisation process address three important aspects.

Firstly, active promotion of reforms of hukou and related systems, and the integration of rural migrants more effectively within the process of urbanisation. In recent years, in response to the issue of 'urbanisation of people,' the State has introduced a number of reform measures for the hukou system to encourage greater integration of agricultural migrants. The State Council, for example, issued the Opinions on Further Promoting the Reform of the Hukou System in 2014. Since 2016, the Interim Regulations on Residence Permit has come into force. In 2016, the General Office of the State Council issued the Proposal to Promote the Settlement of 100 Million Non-Resident Population in Cities. As a result, various departments have issued a series of supporting policies and measures in a concerted effort to solve the practical issues of education, employment, medical and old-age care, and housing security for rural migrants, as well as the practical issues of withdrawal of 'three rights' ${ }^{1}$ in rural areas for those workers who settled in cities. The provinces and central cities have also introduced corresponding plans to implement the reform of hukou systems. Through such reform, the urbanisation rate of the hukou registered population reached $43.37 \%$ in 2018 , and the urbanisation rate of the permanent resident population was synchronously increased. By November 2018, more than 75 million residence permits were issued throughout the country. The six basic public services and seven facilities stipulated in the Interim Regulations on Residence Permits have been implemented in various places, and efforts have been made to expand the scope of basic public services and improve service standards. With deeper and wider reforms of hukou and related systems, the goal of 'Three hundred million people'2 has been gradually implemented.

The second measure concerns the steady promotion of land systems reform so as to improve efficiency and create co-ordinated development of the process of urbanisation affecting both land use and people. Urban population growth and urban sprawl

\footnotetext{
${ }^{1}$ This refers to rural workers who have settled in cities and voluntarily relinquished rural land contracting rights, homestead use rights, and collective income distribution rights with compensation according to regulations.

${ }^{2}$ In March 2014, the 'Government Work Report' reviewed and approved by the 12th National People's Congress pointed out that in the coming period, we should focus on 'Three hundred million people', that is, to promote about 100 million agricultural migrant population settled in towns, renovate urban shanty towns and urban villages where about 100 million people live, and guide about 100 million people to urbanise in the central and western regions.
} 
are the main manifestations of urbanisation. In recent years, the State has issued a number of policies to promote land systems reform so as to achieve 'people-land linkage' in the process of urbanisation. In 2014 the General Office of the Communist Party of China Central Committee and the General Office of the State Council issued the Opinions on the Pilot Work of Rural Land Acquisition, the Market Entry of Collective Business Construction Land, and the Reform of Homestead Land System. The aim was to actively explore the entry of collective construction land and rental property in rural areas into the open market. In 2017, the Ministry of Land and Resources and the Ministry of Housing and Urban-Rural Development jointly issued the Pilot Programme for Building Leased Housing by Collective Construction Land. In 2018, the Communist Party of China Central Committee and the State Council issued the Opinions on Implementing the Rural Vitalization Strategy, clearly specifying the policy of 'improving the idle homestead and idle farm houses,' and exploring the 'Separation of ownership, qualification and use rights of the homestead.' This has set the direction for the reform of rural land systems. On this basis, the Ministry of Land and Resources issued the Notice on Actively Supporting Poverty Alleviation and Development and Relocation of Ex-situ Pro-poverty by Making Good and Flexible Use of Increase and Decrease Linking Policy in 2016. The General Office of the State Council printed and distributed the Measures for the State's Overall Management of Supplementary Arable Land Across Provinces and Regions and the Measures for the Adjustment Management of Balanced Indicators of Increase and Decrease Linking for Land Used for Urban-rural Construction Projects Across Provinces and Regions in 2018. This could expand the transaction scope of balanced indicators of land used for urban-rural construction projects. It was conducive to improving land-use efficiency and achieving a co-ordinated development of urban population growth and urban sprawl.

The third measure comprises the co-ordinated adoption of new strategies for urbanisation and rural development that accelerate the process of integration. Since the 19th National Congress of the Chinese Communist Party in October 2017, there has been a more pronounced two-way flow between urban and rural initiatives. The characteristics of intergenerational migration ${ }^{3}$ in both urban and rural areas have become more apparent, indicating that the process of urbanisation has entered a transitional period of greater integration. The report of the 19th National Congress of the Communist Party of China put forward the Implementation of Rural Vitalization Strategy for the first time, highlighting the need for greater integration of urban-rural development. The Strategy also recognised the need to modernise agricultural industries and improve the quality of life of rural communities. The Opinions of the Central Committee of the Communist Party of China and the State Council on the Implementation of Rural Vitalization Strategy further clarified the significance, objectives, and priorities of implementing new strategies for rural development. Subsequently, the Central Committee of the Communist Party of China and the

\footnotetext{
${ }^{3}$ Since many migrant workers have not obtained urban registration, they will return to their hometowns when they reach a certain age and revert to their previous status as rural workers once more.
} 
State Council jointly issued the Opinions on Establishing and Improving the System, Mechanism and Policy System for the Integration of Urban-rural Development in April 2019. As a result, all regions began to implement in-depth rural vitalisation strategies and establish and improve institutional mechanism and policy systems in order to integrate urban-rural development more comprehensively.

\subsection{Impact of Urbanisation on Rural Poverty Reduction}

With the rapid advancement of urbanisation and large-scale rural-urban migration, China's economy has continued to grow rapidly. The income of urban and rural residents has increased sharply, and the most chronic rural poverty level has decreased drastically. The decrease in rural poverty has contributed more than $70 \%$ to global poverty reduction (Wei and Huang 2019).

\subsubsection{Poverty Reduction in Rural Areas}

The Chinese government attaches great importance to poverty reduction in rural areas. It has invested a great deal of manpower, material and financial resources to help accelerate rural development and achieve prosperity. As a result, levels of rural poverty have decreased significantly across the country. According to the 2010 rural poverty standard (2,300 yuan per person per year), in constant prices, the rural poor population dropped from 770.39 million in 1978 to 16.6 million in 2018, and the poverty incidence decreased from $97.5 \%$ to $1.7 \%$ (see Fig. 5.3). During this period, the rural poor population decreased by 754 million, with an average annual

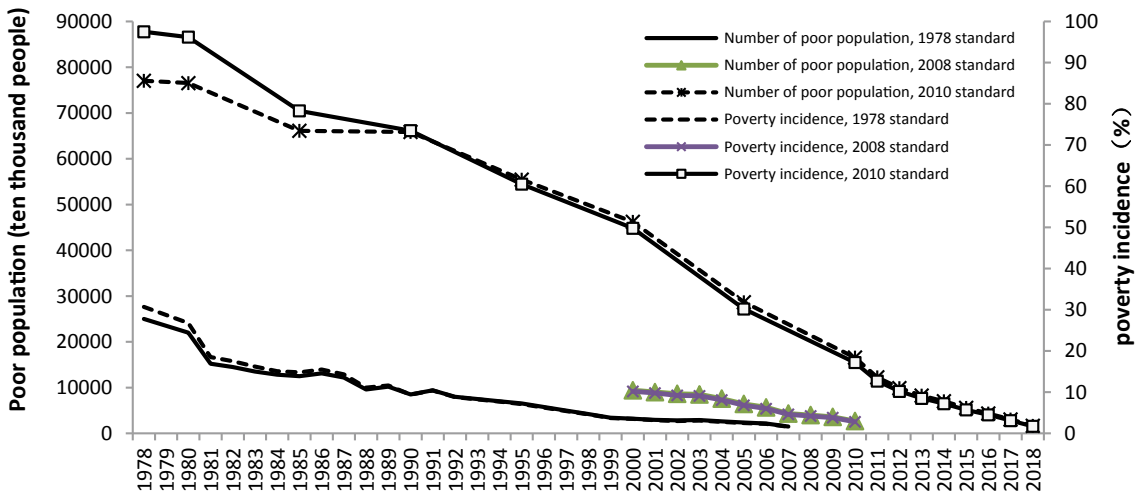

Fig. 5.3 Changes in rural poor population and poverty incidence in China (1978-2018). Data sources Calculated according to China Statistical Yearbook (2018) and the Statistical Communique on the 2018 National Economic and Social Development of the People's Republic of China 
reduction of 18.84 million. The incidence of poverty decreased by 95.8 percent, with an average annual decline of 2.40 percent. This is the only example of a 40 -year process of sustained poverty reduction in the world. The consistent reduction in levels of poverty can be attributed to three general effects:

- Sustained and rapid economic growth, crucial for rural poverty alleviation.

- Sustained and rapid internal migration to urban areas resulting in increased prosperity.

- The government's application of active measures to reduce rural poverty tailored to address specifically Chinese factors and characteristics. According to the standard of Purchasing Power Parity (PPP) of US\$1.9 per day in 2011, China has contributed $71.82 \%$ of the reduction in the world's 1.10 billion poverty-stricken population from 1981 to 2012 ( $\mathrm{Li}$ and Wei 2016).

The fastest rate of poverty reduction has taken place in the east of the country, while the western region has seen poverty reduce by the largest scale. From 2010 to 2018 , China's rural poor population fell by $90 \%$, with the highest reduction of some $94.3 \%$ in the eastern region, and only about $89 \%$ in the central and western regions (see Table 5.2). During this period, the numbers of rural poor decreased by

Table 5.2 China's rural poor population and its distribution from 2010 to 2018

\begin{tabular}{|c|c|c|c|c|c|c|c|c|}
\hline & \multicolumn{4}{|c|}{ Poor population (ten thousand) } & \multicolumn{4}{|c|}{ Distribution of poor population $(\%)$} \\
\hline & Nationwide & $\begin{array}{l}\text { Eastern } \\
\text { China }\end{array}$ & $\begin{array}{l}\text { Central } \\
\text { China }\end{array}$ & $\begin{array}{l}\text { Western } \\
\text { China }\end{array}$ & Nationwide & $\begin{array}{l}\text { Eastern } \\
\text { China }\end{array}$ & $\begin{array}{l}\text { Central } \\
\text { China }\end{array}$ & $\begin{array}{l}\text { Western } \\
\text { China }\end{array}$ \\
\hline 2010 & 16,567 & 2587 & 5551 & 8430 & 100 & 15.6 & 33.5 & 50.9 \\
\hline 2011 & 12,238 & 1655 & 4238 & 6345 & 100 & 13.5 & 34.6 & 51.9 \\
\hline 2012 & 9899 & 1367 & 3446 & 5086 & 100 & 13.8 & 34.8 & 51.4 \\
\hline 2013 & 8249 & 1171 & 2869 & 4209 & 100 & 14.2 & 34.8 & 51.0 \\
\hline 2014 & 7017 & 956 & 2461 & 3600 & 100 & 13.6 & 35.1 & 51.3 \\
\hline 2015 & 5575 & 653 & 2008 & 2914 & 100 & 11.7 & 36.0 & 52.3 \\
\hline 2016 & 4335 & 490 & 1594 & 2251 & 100 & 11.3 & 36.8 & 51.9 \\
\hline 2017 & 3046 & 300 & 1112 & 1634 & 100 & 9.9 & 36.5 & 53.6 \\
\hline 2018 & 1660 & 147 & 597 & 916 & 100 & 8.9 & 35.9 & 55.2 \\
\hline Change & $-14,907$ & -2440 & -4954 & -7514 & & \multirow[t]{2}{*}{$-6.7^{\mathrm{a}}$} & \multirow[t]{2}{*}{$2.4^{\mathrm{a}}$} & \multirow[t]{2}{*}{$4.3^{\mathrm{a}}$} \\
\hline $\begin{array}{l}\text { Growth } \\
(\%)\end{array}$ & -90.0 & -94.3 & -89.2 & -89.1 & & & & \\
\hline
\end{tabular}

$a$ means a percentage point

Note Unit a is a percentage point. Eastern China includes Beijing, Tianjin, Hebei, Liaoning, Shanghai, Jiangsu, Zhejiang, Fujian, Shandong, Guangdong, and Hainan; Central China includes Shanxi, Jilin, Heilongjiang, Anhui, Jiangxi, Henan, Hubei, and Hunan; Western China includes Inner Mongolia, Guangxi, Chongqing, Sichuan, Guizhou, Yunnan, Tibet, Shaanxi, Gansu, Qinghai, Ningxia and Xinjiang

Data sources Calculated according to the annual China Statistical Yearbook and China Statistical Summary, and Wei and Huang (2019) 
149.07 million, by some $50.4 \%$ in the western region, $33.2 \%$ in the central region, and only $16.4 \%$ in the eastern region. Because of the rapidity of poverty reduction in the eastern region, the proportion of the rural poor in that region has gradually declined in recent years, while the proportion across the central and western regions has been rising. Since 2017 , over $90 \%$ of China's rural poor have been concentrated in the central and western regions. In 2018 the western region accounted for $55.2 \%$ of the total, with a poverty incidence of $3.2 \%$. The central region accounted for $35.9 \%$, with a poverty incidence of $1.8 \%$; and the eastern region accounted for only $8.9 \%$, with a poverty incidence of $0.4 \%$. From the perspective of provincial administrative regions, the poverty incidence in all provinces generally fell below 6\% in 2018 . Incidence of poverty in Guizhou, Tibet, Gansu and Xinjiang was over 5\%, while in Shanxi, Henan, Guangxi, Yunnan, Shaanxi, Qinghai and Ningxia it lay between 2 and 5\%. The poverty incidence in Beijing, Tianjin, Shanghai, Jiangsu, Zhejiang, Fujian, Shandong, and Guangdong has dropped to less than $0.5 \%$ (Wei and Huang 2019).

\subsubsection{The Role of Urbanisation in Poverty Reduction in Rural Areas}

Urbanisation has played an active role in rural poverty reduction, mainly through promoting economic and social development and labour transfer in poverty-stricken areas. The process has raised the income level of rural residents, increased the non-agricultural income of rural dwellers, and gradually narrowed the income gap between urban and rural areas. The means by which urbanisation reduces rural poverty can be divided into three aspects.

- First, the attraction of urban centres as places of employment and increased integration of urban and rural development drives economic and social development in rural areas and increases income levels. Shen and Jiang (2007) use China's provincial panel data and analyse the positive impact of urbanisation on economic growth, which increases income levels and reduces poverty. Chen et al. (2010) proved the positive correlation between urbanisation and economic development at a provincial level.

- Secondly, an increase in non-agricultural income will increase wages or transfer income from family members employed in sectors other than agriculture. Ahluwalia (2008) argues that by primarily increasing income levels, urbanisation is an important condition for poverty reduction.

- Thirdly, urbanisation involves large-scale internal migration from rural areas leading a reduction in the population of the rural poor. This can also lead to the problem of urban poverty which will be discussed in the next section. This process can be called the transfer effect of urbanisation on poverty reduction. Wang (2008) considers that this transfer effect is achieved by means of 'urbanisation - transfer of rural labour -poverty alleviation.' Calì and Menon (2016) 
believe that urbanisation reduces rural poverty mainly through the transfer of rural poor population to urban areas, which reduces both the rural poor population and the total rural population. Wan et al. (2017) argue that urbanisation can not only effectively reduce the poverty of rural and migrant workers, but also help to narrow the urban-rural income and consumption gaps. Some scholars suggest that whether urbanisation can reduce poverty is related to the particular stage of urbanisation involved. The early stage of the urbanisation process is conducive to poverty reduction, while later stages have less impact on reducing levels of poverty (Panudulkitti 2007; Cui and He 2018).

As Chinese reforms gathered pace from the 1980s, rural workers followed a pattern of temporary migration-'departing farming without leaving native land.' By the beginning of the 1990s the scale of trans-provincial flow of labour gradually increased. After 2000 the rural surplus labour force began to migrate on a large scale and to settle in cities more permanently. The process of 'rural workers moving into cities' has both greatly improved their income and living standards and narrowed the income gap between urban and rural residents, while providing a sufficient labour force for economic development. The per capita wage income of rural households and its proportion of workers' per capita net income have both increased rapidly, from 152 yuan or $21.4 \%$ in 1991 to 772 yuan or $32.6 \%$ in 2001, and then to 3448 yuan or $43.6 \%$ in 2012 (see Fig. 5.4), making a significant contribution to the increase of per capita income of rural households. By contrast, the proportion of household operating income fell from $73.9 \%$ in 1991 to $44.6 \%$ in 2012 . Since 2013 , the National

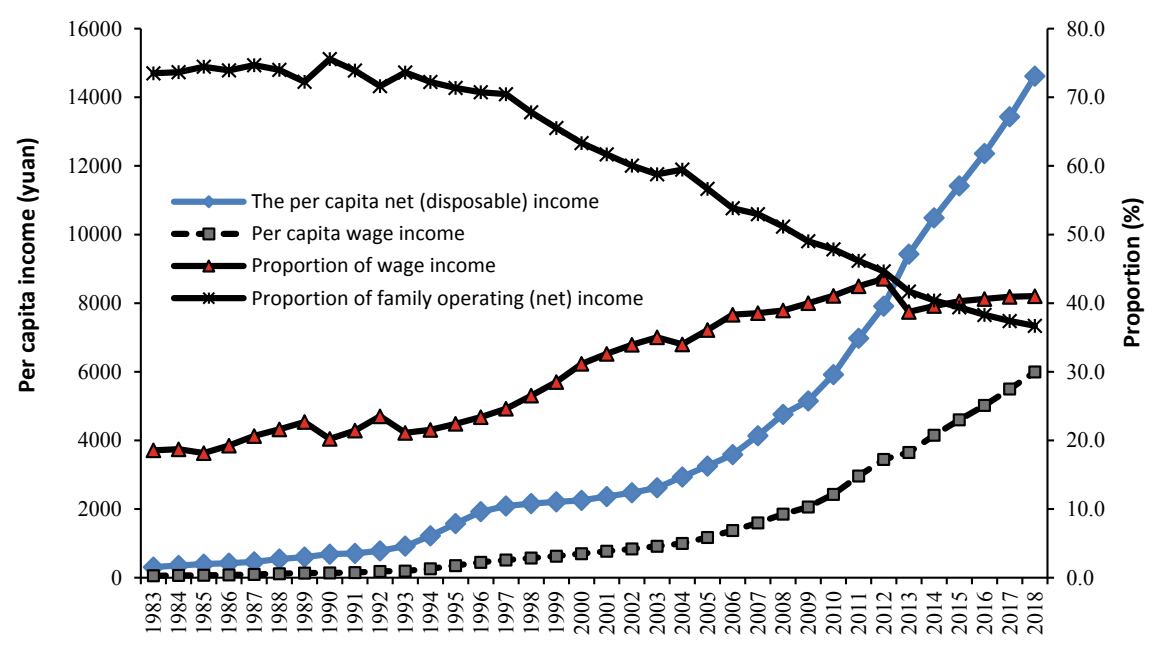

Fig. 5.4 Changes in per capita income of rural households in China (1978-2018). Note Due to the adjustment of statistical calibrations, the data before 2013 refers to the per capita net income of rural households, and the data since 2013 refers to per capita disposable income of rural households. Data sources Calculated and collated by the authors according to the China Statistical Yearbook (corresponding years) and China Statistical Summary (2019) 
Bureau of Statistics has surveyed integrated household income, expenditure and living conditions in urban and rural areas, and revised the statistical calibration of farmers' income, principally adjusting farmers' per capita net income to the per capita disposable income of rural residents. From 2013 to 2018, the proportion of wage income within rural households' per capita disposable income increased from 38.7 to $41 \%$. The proportion of net transfer income increased from 17.5 to $20 \%$, while the proportion of net income from household operations decreased from 41.7 to $36.7 \%$. The income earned by farmers leaving agriculture and rural areas to work in cities forms a significant proportion of this increase. It follows that the rapid growth of farmers' main income in recent years comes from the growth of wages and net transfer income from urban migration. During 2014 and 2018, nearly 70\% of the increase of rural residents' per capita disposable income came from wage income and net transfer income, of which the contribution of wage income to the increase of farmers' income was $45.2 \%$, and that of net transfer income was $24.5 \%$.

With urbanisation and population migration, the income gap between urban and rural residents has fluctuated and expanded continuously. It has gradually stabilised and narrowed from 2003 (see Fig. 5.5). In the early stages of reform and the implementation of the rural household contract responsibility system, farmers' income increased rapidly, and the urban-rural income gap narrowed. However, since the focus of economic reform shifted in 1985 from rural to urban areas, the urban-rural income gap began to expand sharply. From 1984 to 2003, the ratio of per capita disposable income for both urban and rural residents expanded rapidly from 1.84 to 3.12. From 2004 to 2019, the Communist Party of China's Central Committee

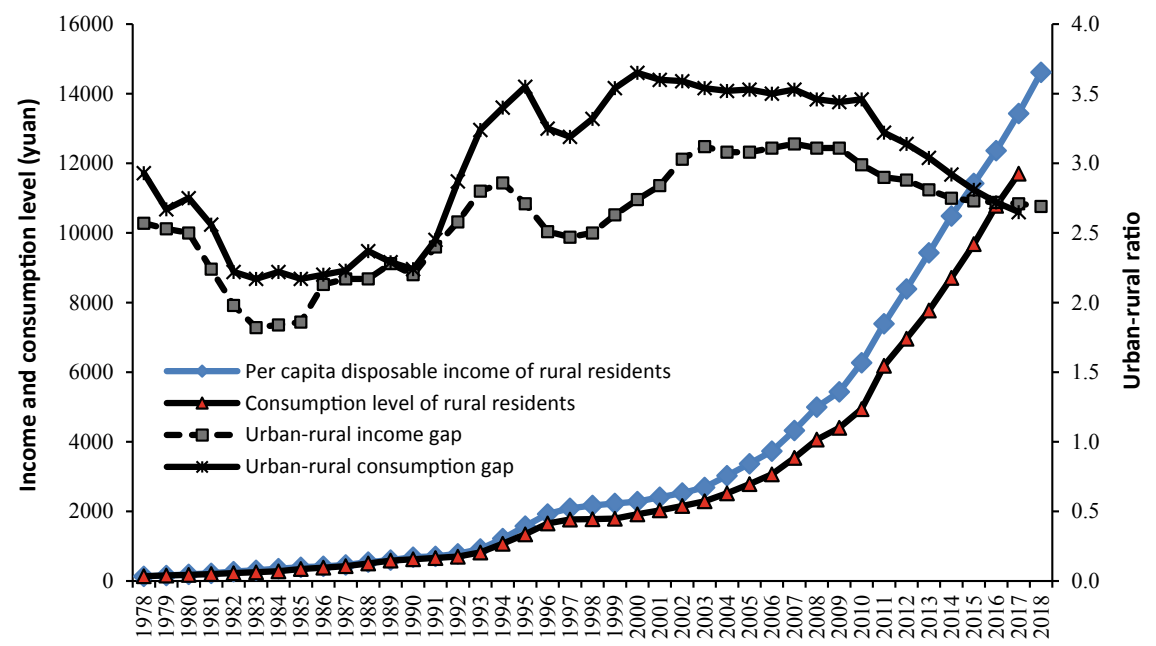

Fig. 5.5 Changes in the income of urban and rural residents in China (1978-2018). Data sources Drawn according to China Statistical Yearbook (2018), China Rural Statistical Yearbook (2018), China Statistical Summary (2018) and the Statistical Communique of National Economic and Social Development of 2018 
successively issued 16 No.1 Documents to support the development of 'agriculture, rural areas and rural residents' and introduced a series of policies to support agriculture and benefit farmers. With the support of central policies, the income of rural residents continued to increase rapidly, and the gap between urban and rural residents' income and consumption levels continued to shrink. In terms of per capita disposable income, the income ratio of urban and rural residents in China dropped from the peak value of 3.14 in 2007 to 2.69 in 2018, while the consumption ratio for urban and rural residents also declined from the peak value of 3.65 in 2000 to 2.65 in 2017. This shows that China has entered a new period in which the gap between urban and rural areas continues to close.

However, it should be noted that the current urban-rural income gap in China remains large. In 2018, the ratio of per capita disposable income of urban and rural residents was still $48 \%$ higher than in 1983. In particular, since an integrated land market has not yet formed, the channels for rural resources to change into capital and wealth are not smooth, and the wealth gap between urban and rural residents is very wide. In 2018, the ratio of per capita net income from capital and wealth of urban to rural residents reached up to 11.8 .

The process of urbanisation correlates both with increases in rural residents' income and anti-poverty measures. Figures 5.6 and 5.7 show the basic correlation between the rate of urbanisation, poverty incidence and the size of the provincial poor population in 2017. It indicates that the higher the urbanisation rate, the lower the incidence of rural poverty and the smaller rural poor population. It can be seen that, in 2017, eastern provinces and cities experienced the highest rates of urbanisation. The rural poverty rate for Beijing, Tianjin, Shanghai, Jiangsu, Zhejiang, Fujian, and Guangdong (at the lower right corner of Figs. 5.6 and 5.7) was 0, and their urbanisation rates were $86.5 \%, 82.9 \%, 87.7 \%, 68.8 \%, 68.0 \%, 64.8 \%$ and $69.9 \%$, respectively.

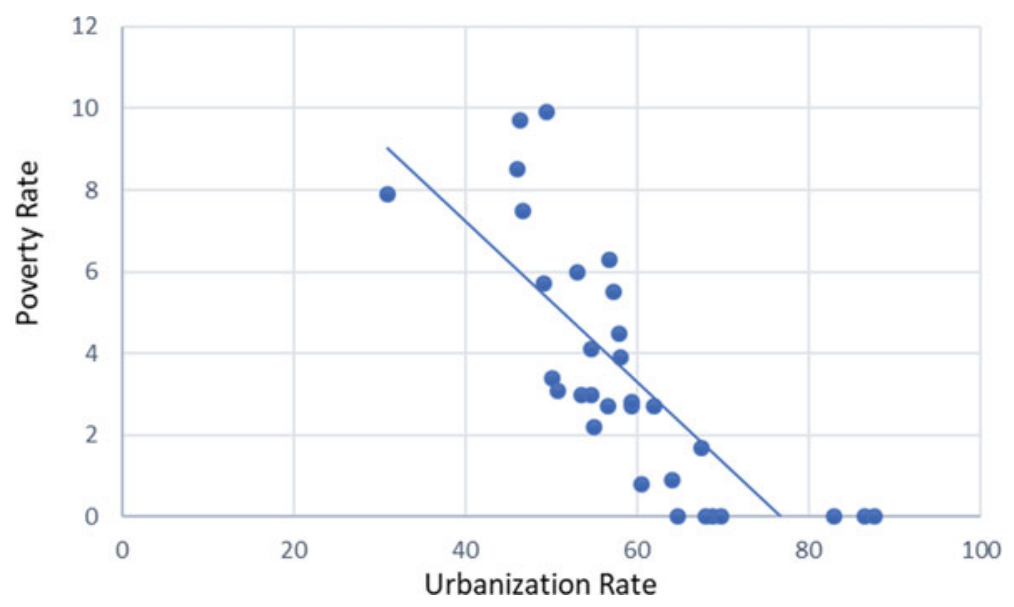

Fig. 5.6 Correlation between urbanisation rate and poverty incidence in rural areas in various regions in 2017. Data sources Drawn according to China Statistical Summary of 2018 


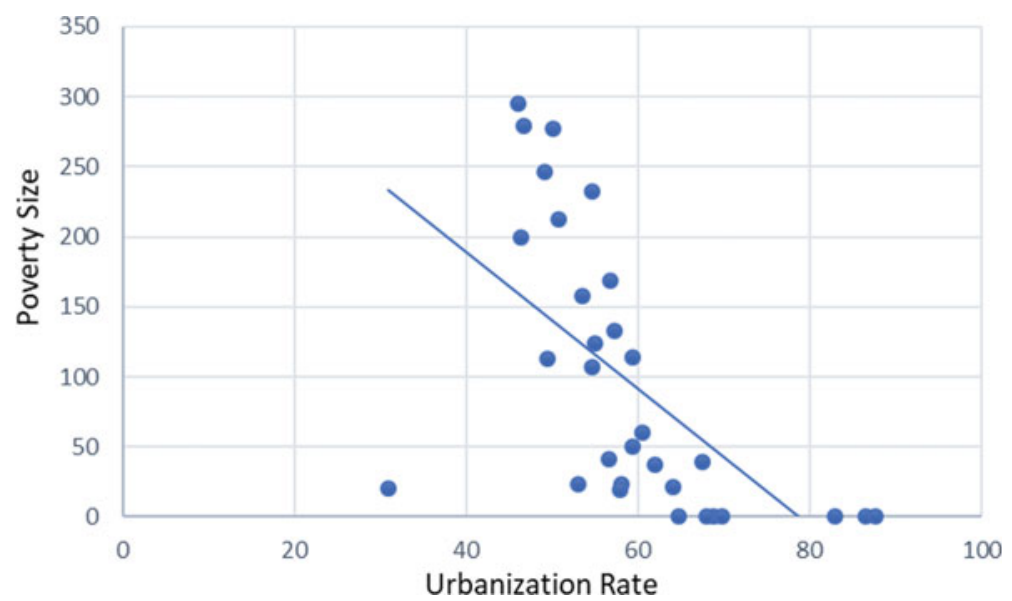

Fig. 5.7 Correlation between urbanisation rate and size of rural poor population in various regions in 2017. Data sources Drawn according to China Statistical Summary 2018

In comparison, the urbanisation rate of the western provinces (autonomous regions) such as Tibet, Gansu, Xinjiang, Guizhou, Yunnan, Guangxi and Qinghai (at the upper left corner of Figs. 5.6 and 5.7) was low, and the poverty incidence in rural areas was high.

This study further uses the panel data of urbanisation rates, the incidence of rural poverty and size of the poor population from 2010 to 2017 to examine the correlation between urbanisation and rural poverty. The result is shown in Table 5.3. In Models $1-6$, we use panel data to analyse the correlation between the urbanisation rate, the incidence of rural poverty and size of the poor population, showing a significant

Table 5.3 Correlation among urbanisation rate, poverty incidence in rural areas and size of poor population

\begin{tabular}{l|l|l|l|l|l|l}
\hline \multirow{2}{*}{} & \multicolumn{3}{l}{ Poverty incidence } & \multicolumn{2}{l}{ Size of poor population } \\
\cline { 2 - 7 } & Model 1 & Model 2 & Model 3 & Model 4 & Model 5 & Model 6 \\
\hline Constant term & $\begin{array}{l}38.0224^{\mathrm{a}} \\
(22.42)\end{array}$ & $\begin{array}{l}60.0987^{\mathrm{a}} \\
(8.32)\end{array}$ & $\begin{array}{l}105.9304^{\mathrm{a}} \\
(24.71)\end{array}$ & $\begin{array}{l}973.3356^{\mathrm{a}} \\
(15.13)\end{array}$ & $\begin{array}{l}2170.217^{\mathrm{a}} \\
(5.89)\end{array}$ & $\begin{array}{l}3163.952^{\mathrm{a}} \\
(24.88)\end{array}$ \\
\hline $\begin{array}{l}\text { Urbanisation } \\
\text { rate }\end{array}$ & $\begin{array}{l}-0.5145^{\mathrm{a}} \\
(-17.18)\end{array}$ & $\begin{array}{l}-0.9158^{\mathrm{a}} \\
(-6.27)\end{array}$ & $\begin{array}{l}-1.7491^{\mathrm{a}} \\
(-22.47)\end{array}$ & $\begin{array}{l}-12.7994^{\mathrm{a}} \\
(-11.27)\end{array}$ & $\begin{array}{l}-34.5598^{\mathrm{a}} \\
(-5.22)\end{array}$ & $\begin{array}{l}-52.6268^{\mathrm{a}} \\
(-22.79)\end{array}$ \\
\hline $\mathrm{F}$ & 295.27 & & 504.91 & 127.10 & & 519.48 \\
\hline $\mathrm{R}^{2}$ & 0.5455 & 0.5455 & 0.5455 & 0.3407 & 0.3407 & 0.3407 \\
\hline Sample & $31 \times 8$ & $31 \times 8$ & $31 \times 8$ & $31 \times 8$ & $31 \times 8$ & $31 \times 8$ \\
\hline Remark & $\begin{array}{l}\text { Mixed } \\
\text { effect }\end{array}$ & $\begin{array}{l}\text { Random } \\
\text { effect }\end{array}$ & $\begin{array}{l}\text { Fixed } \\
\text { effect }\end{array}$ & $\begin{array}{l}\text { Mixed } \\
\text { effect }\end{array}$ & $\begin{array}{l}\text { Random } \\
\text { effect }\end{array}$ & $\begin{array}{l}\text { Fixed } \\
\text { effect }\end{array}$ \\
\hline
\end{tabular}

Note The numbers in the parentheses refer to t-value or z-value

aindicates significance at $1 \%$ level 
negative correlation. That means, the higher the urbanisation rate, the lower the poverty incidence in rural areas, and the smaller the size of the poor population. Considering that the urbanisation rate is the only explanatory variable, in models 3 and 6 we adopt a fixed-effect model to control for time-invariant omitted variables. As such, the coefficients of Model 3 and Model 6 are the preferred models for interpretation. The coefficients reported in Table 5.3 show that for every 1 percentage point increase in the urbanisation rate, the poverty incidence in rural areas reduces by about $1.75 \%$ (Model 3), and the size of the rural poor population reduces by about 526,300 (Model 6).

\subsection{Urban Poverty in the Process of Migration and Urbanisation}

The active role played by urbanisation in rural poverty reduction can be partly attributed to the migration of population from rural to urban areas, that is, the migration effect of urbanisation in poverty reduction. Nevertheless, migrants who settle in cities often face a variety of barriers that can lead them into urban poverty. During the process of rapid urbanisation and large-scale demographic migration, the national poverty reduction strategy develops from an early countryside-oriented strategy to one that lays equal stress on urban and rural areas. It will then change emphasis to become a city-oriented poverty reduction strategy (see Fig. 5.8), along with a shift in rural poverty and urban poverty. Current anti-poverty measures in China have entered a new stage of co-ordinated urban-rural management. It should be emphasised that,

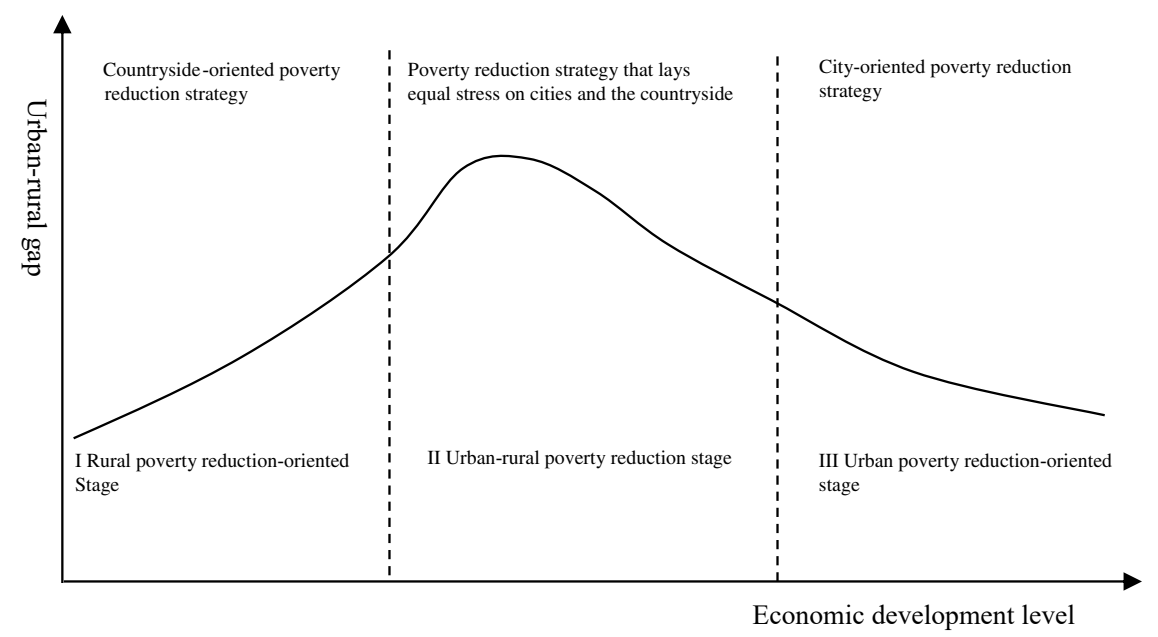

Fig. 5.8 Economic development and poverty reduction strategy. Source Wei (2018) 
although some rural-urban migrants live in poverty, Chinese cities have not experienced the emergence of 'slums' like other countries in the process of large-scale rapid urbanisation. This can be attributed to continuous strengthening of the policy support for 'going into the city' and the policy guarantee of 'returning home' ${ }^{4}$ for rural-urban migrants in China. The policies enable Chinese farmers to realise urbanisation in an orderly manner and a two-way flow process of 'moving into the city and returning home smoothly'.

At present, official statistics for the size of the urban poor population mainly cover the lower-income urban registered population. Estimates for transient or migrant populations are often based on sample surveys. In general, the lower-income population with local urban hukou has been decreasing, and poverty levels among the urban floating population have increased. Growth in floating populations with presumed high levels of poverty and the problems of relative and multidimensional poverty are more significant. Further studies on the size, structure and distribution of poverty among permanent urban residents are needed in order to gain a clearer picture.

\subsubsection{Estimation of Poverty Rates Among the Urban Hukou Registered Population}

Currently, China lacks a unified standard for measuring levels of urban poverty. Consequently, any estimation of the size of the urban poor population will vary according to the different standards used. To all intents and purposes, a measure based on urban minimum living standards (only covering the hukou registered population) acts as yardstick for levels of urban poverty. This standard is generally the first to be applied, with other measures added according to circumstances. In order to properly assess and resolve issues around living standards among the urban poor, the State Council issued the Notice on Establishing the Minimum Living Security System for Urban Residents Across the Country on September 2, 1997. Since then, all levels of government have gradually established and improved their policies for dealing with minimum living standards in urban areas.

It can be seen from Fig. 5.9 that the number of hukou registered population guaranteed by the minimum standard of living increased gradually from the time the new system was introduced. By 2002, numbers had stabilised to around 20 million. Since 2009, the trend has decreased, falling to the level of 2002 in 2013 and continuing to decrease. By 2018, the number of urban dwellers living at the minimum standard had fallen to 10.08 million.

\footnotetext{
${ }^{4}$ On the one hand, it supports their return to hometown for employment and entrepreneurship and promotes urbanisation locally; on the other hand, it supports basic public services for them to enjoy equalisation in cities. At the same time, it maintains land contracting rights, homestead use rights, and collective income distribution rights for the rural migrant workers who become urban residents, and promotes an orderly process of citizenisation.
} 


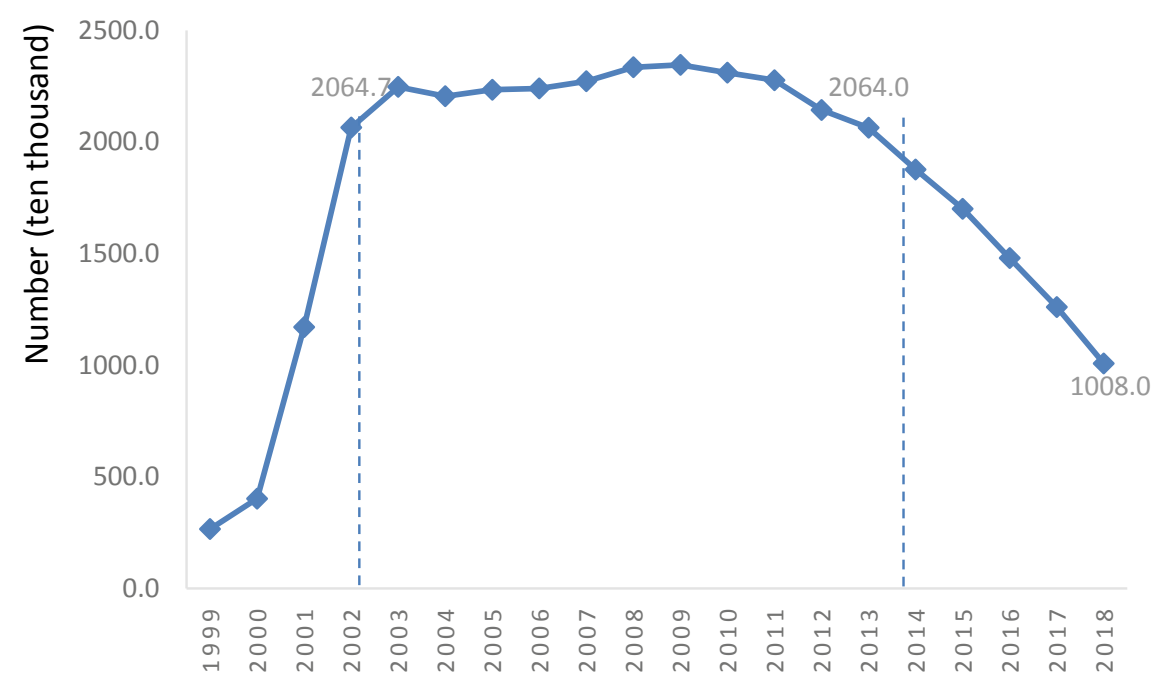

Fig. 5.9 Urban poverty: Chinese urban population living at the minimum living standard (19992018). Data sources Collated according to relevant data from China Statistical Yearbook

\subsubsection{Estimating the Scale of Urban Poverty Including Migrant Populations}

According to the early studies of the World Bank (1993), the numbers of urban poor in China ranged from 500,000 to 3.9 million between 1981 and 1990, with an average poverty incidence rate of $0.5 \%$. Since there is currently no unified standard for measuring urban poverty, Chinese analysts and scholars use different methods to estimate urban poverty, and results vary greatly (Wei et al. 2016).

Comparing these results, we find that:

- The size of the poor population calculated for individual years is much larger than that obtained according to the urban minimum living security standard.

- The size of the poor population calculated according to consumption and expenditure is much larger than that calculated according to the income standard.

- Thirdly, due to limited data, the large number of people who make up the 'floating population' in cities are missing from the calculations. The number of poor rural migrants in cities cannot be counted accurately. Consequently, the scale of urban poverty has been underestimated to a certain extent. At present, estimates on the size of the floating population are mostly conducted by sampling methods across individual regions; therefore limited knowledge is available concerning the size and distribution of the floating population at the national level.

According to the existing studies, the poverty rate among the floating population is higher than that across the original urban residents. Estimates of the incidence of urban poverty will increase and the estimated size of the population of urban poor 
will significantly increase when the floating population is taken into consideration. For example, the study by $\mathrm{Du}$ ( 2007) shows that the poverty rate of the floating population is slightly higher than that of urban local residents, at $10.3 \%$ and $8.7 \%$, respectively. Research by $\mathrm{Li}$ (2002) shows that the national average poverty rate among the floating population is $15.2 \%$. The study also finds that its proportion in some cities is even higher than $20 \%$. The average poverty rate among the floating population is about $50 \%$ higher than that of the urban registered population. Based on a review of the actual situation and general living expenses standards, Ma (2005) used the national per capita living expenses indicator to classify the urban poor population. If rural migration into cities were to be taken into consideration, the poverty incidence rate would be estimated at $11 \%$ in 2003 and the urban poor population at 60 million.

\section{(1) Estimation based on the existing results}

We use existing studies to estimate the current scale of urban poverty. According to the survey by Du (2007), the poverty incidence of the floating population is slightly higher than that of urban residents, but the two are roughly the same. This is mainly due to the mobility of the floating population between urban and rural areas, and consequently, urban poverty is a result of the choice of living location. When their urban living standard is low, rural migrants choose to return to their hometowns. The research by Wang (2011) also shows that the income of the floating population is at times even higher than that of local residents. This is mainly because they work long hours and intensively, but the income per unit time may be lower than that of local residents. In addition, the urban poverty rate, even estimated according to the US\$2 a day international poverty standard, remains at more than $8.5 \% .^{5}$

Using this criterion, we make a conservative estimate of a poverty rate of $8-10 \%$ based on income. In 2014, China's urban population was 749 million, with a poor population of between about 60 million and 75 million, comprising about 18 million 'registered' citizens and a floating 'unregistered' population of between about 42 million and 57 million.

(2) Estimation based on a sample survey

In order to investigate poverty levels among the urban floating population and estimate the numbers of poor migrant workers, we designed a questionnaire based on the experience of previous studies. We modified and improved the questionnaire design during pre-survey tests, and conducted a sample survey among migrant workers in Beijing, Shenzhen and Huizhou. We distributed a total of 1800 formal survey questionnaires and received a total of 1305 valid questionnaires in response, excluding invalid returns and responses from residents staying in cities for less than half a year.

We estimated the size of the poor population in the survey results. The floating population was not covered by the urban minimum living security standard at the time of the survey, nor were they completely covered by urban public services. Their poverty can therefore be described as 'multidimensional

\footnotetext{
${ }^{5}$ In October 2015, the World Bank adjusted the international poverty standard from US $\$ 1.25$ and $\$ 2$ to US\$1.9 and \$3.1, respectively.
} 
poverty' or relative poverty compared to urban residents. The scale of the relatively poor population is larger than that of the absolute poor population. The poverty rate calculated according to the relative poverty standard is correspondingly higher than the indicator value obtained according to the absolute poverty standard.

Based on the previous research experience, we adopted a standard of $50 \%$ of local residents' per capita consumption expenditure in that year to measure levels of poverty. A total of 263 poverty samples were identified, with an overall incidence of poverty at around $20.15 \%$. Based on this, according to the $20 \%$ poverty incidence of migrant workers, we estimated that the total number of migrant workers in China was about 274 million in 2014, and the number of migrant workers in poverty was about 55 million. The estimated results are in the range of $8-10 \%$ of urban residents living in poverty which accords to the most credible estimates.

Thus, it can be seen that the size of the 'registered' population of urban poor has decreased in recent years, while that of poor migrant workers has increased. In 2015 , the population of urban 'registered' poor was about 17 million, and poor migrant workers around 55 million, accounting for around $75 \%$ of the total of urban poor. Without effective measures to alleviate poverty among migrant workers and accelerate the process of citizenship, it is likely that the problem of rural poverty will shift to cities.

\subsubsection{Other Dimensions of Poverty Among Urban Migrant Workers}

Sen (1981) argues that poverty means low levels of wealth and the loss of the ability to acquire more due to inequalities in economic status. Based on existing studies, combined with the results of our questionnaire survey, we recognise that the quality of life of urban migrant workers needs to be improved in terms of the nature of work, family income and expenditure, living conditions, social security and children's education (Wei et al. 2016; see also Chap. 14). The first dimension, the nature of work, comprises low wages, long working hours and low skills. First of all, wage levels are low. Restricted by educational levels, lack of personal skills and information acquisition, poor migrant workers still greatly rely on their relatives and friends to get jobs, and usually have to sell their labour cheaply. Long working hours are also an issue. The survey found that $21.1 \%$ of the poor population worked more than eight hours per day, and nearly $10 \%$ worked more than $10 \mathrm{~h}$ per day. A third point is their low level of job skills. Nearly half of all poor migrant workers have not participated in any form of vocational training, and most of them are engaged in jobs with low technical requirements, such as nannies, waiters, or in industries with relatively difficult and dangerous conditions, such as construction, transportation, handling and loading. 
The second dimension involves issues like small living spaces with relatively backward facilities. According to the survey, the living area per capita housing for urban poor migrant workers was only $11.73 \mathrm{~m}^{2}$, less than half of the national average for urban residents $\left(32.91 \mathrm{~m}^{2}\right)$. More than $20 \%$ of urban poor migrant workers lived in simple housing, basements or semi-basements, and nearly $70 \%$ lived in dormitories or one-bedroom apartments, with narrow living space and a tough living environment. The housing quality indicator for poor migrant workers was only 0.47 , measured by the average ownership rate of various housing facilities (televisions, the internet, toilets, bathing facilities, refrigerators, air conditioners, etc.). That is lower than the sample average value of 0.58 .

Thirdly, the proportion of rural migrants claiming social security is lower than that of urban residents, which exacerbates their poverty. According to the survey, only $27.80 \%$ of urban poor migrant workers have actively participated in unemployment insurance schemes, and $48.65 \%$ of them have taken out work-related injury insurance. $17.76 \%$ of them have not participated in any form of medical insurance, and $16.99 \%$ have no form of pension insurance. Poor migrant workers have a strong requirement for social security assistance, and $40-50 \%$ of respondents considered that the level claiming social security needs to increase.

A fourth element is the proportion of children who do not receive any form of education where their parents or carers work. According to the survey, 57.4\% of urban poor migrant workers are compelled to leave their children in their hometowns to receive education because of their exclusion from hukou or higher tuition fees where their parents work. Currently, a high proportion of children living with their migrant worker parents are either too young for school, have dropped out of education or else reached the legal working age. Many children of migrant workers have to return to their registered permanent residence for schooling. The survey results also show that the demand among married migrants for their children's education $(50.77 \%)$ is higher than that of the total samples $(43.37 \%)$.

At the same time, poverty seriously impedes the willingness of poor migrant workers to stay in cities. Urban poor migrant workers show a low level of willingness to settle in cities (24.69\%), mainly due to high living costs $(71.67 \%)$ and issues around hukou problems $(38.20 \%)$. Consequently, poorer people give less consideration to factors affecting where their children live. Among the respondents, 50.75\% have not considered this issue, which is directly related to their lower willingness to stay in cities.

For further discussion on the multidimensional nature of deprivation, see Chap. 14 which sets out the theoretical basis for indices of multiple deprivation and offers practical guidelines for estimating them in a Chinese context. 


\subsection{Conclusion}

Since China's Reform and Opening-up, the country's rapid urbanisation and largescale internal migration have greatly contributed to social developments and the promotion of well-being. From 1978 to 2017, China's permanent urban population increased from 172 to 813 million, with an increase of 641 million in the overall population. This accounted for $26 \%$ of the world's new urban population in the same period. At the same time, in the context of China's rapid economic and social growth, benefiting from both income and transfer effects in the process of urbanisation, China's rural poor population has decreased by 754 million over the past 40 years. This marks a contribution of more than $70 \%$ to the reduction of global poverty, an unprecedented and almost miraculous decrease in levels of human poverty.

In recent years, levels of poverty within urban hukou populations in China has continuously decreased. In contrast, levels of chronic poverty among migrant workers has continued to grow, accounting for about $75 \%$ of the total population of urban poor. The urban poor population has been increasing in proportion with total urban numbers, and the multidimensional characteristics of their poverty are significant (see Chaps. 14 and 15).

As a result, measures to tackle issues of urban/rural inequalities and challenges around population flows from rural to urban areas and back, have entered a new stage of higher quality development. In the future, China needs to prioritise these new challenges, increasing levels of 'citizenship', urban-rural integration, and co-ordinated poverty management, so as to achieve high-quality development and interventions.

Firstly, to address the problem of 'incomplete urbanisation', China will have to accelerate the pace of increasing levels of citizenship and reforming the hukou system. China suffers from significant structural contradictions in the process of increasing citizenship. There are higher barriers for permanent settlement in megacities, while rural migrants are less willing to settle in small and medium-sized cities. To improve the reform of institutional mechanisms, such as hukou, land and public services, China should continue to steadily promote the reform of relevant systems, accelerate the process of citizenship for rural migrants. The aim must be to narrow the gap between the urbanisation rate among hukou registered and permanent populations and migrant workers. Allied to the provision of more adequate and equal public services and social security, these measures need to focus on comprehensively improving the well-being of various groups.

Secondly, to address the imbalance between urban and rural development, China will need a coordinated policy response. This will entail improving the level of urban-rural integration and development through the implementation of innovative programmes to revitalise both rural and urban areas. This will help improve the quantity and quality of capital resources, and encourage labour to flow back into the countryside. Both rural and urban land need to be utilised more effectively and comprehensively to facilitate greater interaction and equality between urban and rural areas. China should also gradually introduce measures to coordinate poverty management and achieve common prosperity across rural and urban areas. 
Since 1978, China has made great strides to tackle rural poverty, but the problems of urban poverty, especially among migrant workers, have become increasingly prominent. In future, based on the great achievements in the reduction of rural poverty, China should accelerate the development of systems to address poverty comprehensively across urban, rural and migrant poor populations. Issues around urban poverty need to be integrated into the scope of appropriate organisations dedicated to the alleviation of poverty. The focus of policy in China seems to be shifting towards the need to address relative and multidimensional poverty and to adopt a comprehensive approach to resolving urban-rural poverty. This will help lay a solid foundation for achieving common prosperity across both urban and rural areas.

\section{References}

Ahluwalia M, et al (2008) Urbanisation, agglomeration, and economic development, vol 3, 3rd edn. Berkeley Programme on Housing \& Urban Policy Working Paper, pp 359-367

Calì M, Menon C (2016) Does urbanisation affect rural poor population? evidence from indian districts. Soc Sci Electron Publ 27(14):171-201

Chen M, Lu D, Liu H (2010) The interprovincial pattern of the correlation between urbanisation and economic development in China. J Geogr Sci 65(12):1443-1453. (in Chinese)

Cui W, He C (2018) The urban poverty reduction effect of urbanisation: theoretical mechanism and empirical test. Econ Sci 4:89-102. (in Chinese)

Du Y (2007) Urban poverty in China: trends, policies and new issues. China Development Research Foundation Report No. 34. (in Chinese)

Li S (2002) Urban poverty in China showing three characteristics. Leadership Decision Information 42:26. (in Chinese)

Li P, Wei H (2016) Annual report on poverty reduction of China, Social Sciences Academic Press. (in Chinese)

Ma C (2005) Research on the poverty issue of urban residents in China. Economist 3:75-82. (in Chinese)

National Health Commission of the People's Republic of China (2018). China Mobile Population Development Report. Beijing: China Population Press. (in Chinese)

Northam RM (1979) Urban geography. 2nd edn. New York: John Wiley \& Sons

Panudulkitti P (2007) How does the level of urbanization matter for poverty reduction? Working Paper, Georgia State University

Sen AK (1981) Poverty and famines: an essay on entitlement and deprivation. Clarendon, Oxford

Shen K, Jiang R (2007) An empirical research on the impact mechanism of urbanisation on eeconomic growth in China. Stat Res 24(6):9-15. (in Chinese)

State Statistical Bureau (2019). China statistical yearbook, Beijing: Chinese Statistics Press

Wan G, Pan H, Zhang Y (2017) Urbanisation, inequality and poverty. J Guangxi Univ Finance Econ 2:1-19. (in Chinese)

Wang M (2011) Labor transfer and urban poverty in China. China International Poverty Reduction Center Research Report, p 4. (in Chinese)

Wang S (2008) Fighting poverty in development-summary and evaluation of China's 30 years of large-scale poverty reduction experience. Manag World 11:78-88. (in Chinese)

Wei H (2013) Some theoretical thoughts on urban society. Urban Dev Res 20(5):24-29. (in Chinese)

Wei H (2014) Taking a new-type urbanisation road with chinese characteristics. Social Sciences Academic Press, Beijing. (in Chinese)

Wei H (2015) Urbanisation in China process and outlook. China Econ 10(2):102-123 
Wei H (2018) New strategy for poverty reduction in China after 2020. Zhongzhou Acad J 261(09):42-48. (in Chinese)

Wei H, Huang B (2019) Analysis and forecast of China's rural economic situation (2018-2019). Beijing: Social Sciences Academic Press. (in Chinese)

Wei H, Su H et al, (2016) Analysis of urban poverty in China. Beijing: China Social Sciences Press. (in Chinese)

Wei H (2019) Urbanisation in China. Springer

World Bank (1993) China: poverty reduction strategy in the 1990s. China Finance and Economics Press, Beijing (in Chinese)

Open Access This chapter is licensed under the terms of the Creative Commons Attribution 4.0 International License (http://creativecommons.org/licenses/by/4.0/), which permits use, sharing, adaptation, distribution and reproduction in any medium or format, as long as you give appropriate credit to the original author(s) and the source, provide a link to the Creative Commons license and indicate if changes were made.

The images or other third party material in this chapter are included in the chapter's Creative Commons license, unless indicated otherwise in a credit line to the material. If material is not included in the chapter's Creative Commons license and your intended use is not permitted by statutory regulation or exceeds the permitted use, you will need to obtain permission directly from the copyright holder. 